\title{
Follow-up on ECMO after Cardiac Surgery: How Can We Evaluate Therapy?
}

\author{
Vusal Hajiyev, Tamerlan Erkenov, Andreas Smechowski, Just Soeren, Dirk Fritzsche
}

Sana-Herzzentrum Cottbus, Cottbus, Germany

\section{INTRODUCTION}

Venoarterial extracorporeal membrane oxygenation (VA-ECMO) provides temporary cardiorespiratory support for patients in cardiogenic shock despite high-dose inotropic therapy and use of an intra-aortic balloon pump (IABP) [Muehrcke 1996]. Postcardiotomy cardiogenic shock has an incidence of $2 \%-6 \%$ after routine adult cardiac surgery [Hernandez 2007]. There are $0.5 \%-1.5 \%$ of patients who are refractory to medical and device therapy, and cardiogenic shock can lead to multiorgan dysfunction and mortality [Rastan 2010]. Prolonged cardiorespiratory support, which can be achieved with ECMO, may provide time for myocardial recovery and prevent multiorgan dysfunction and reduce mortality [Smedira 2001]. However, this device is associated with serious complications [Khorsandi 2017]. The reported survival rate on ECMO is 36\% [Biancari 2018].

The aim of this study is to follow up on factors that can influence therapy outcome for patients who receive VAECMO after cardiac surgery.

\section{MATERIALS AND METHODS}

This is a retrospective single-center cohort study.

We analyzed factors that can possibly influence the mortality of patients on VA-ECMO after cardiac surgery. Follow-up on parameters such as lactate, noradrenalin dose, mean arterial pressure, $\mathrm{pH}$, central venous oxygen saturation ( $\mathrm{SvO} 2)$, CK, CRP, and creatinine was done at different time points (preoperatively; before ECMO implantation; at 2 hours, 24 hours, and 48 hours after implantation; during explantation; and at 24 hours after explantation) on 23 patients who had undergone cardiac surgery and received VA-ECMO because of postcardiotomy shock in our center between January 2017 and October 2017.

All operations were performed by using median sternotomy, and myocardial protections were done by using antegrade warm blood cardioplegia

The decision for ECMO implantation was based on failure to respond to standard hemodynamic support.

Peripheral cannulation was done by using open surgical technique through arteria femoralis and vena femoralis and

Received August 6, 2018; accepted September 14, 2018.

Correspondence: Vusal Hajiyev, Sana-Herzzentrum Cottbus, Leipzigerstr. 50, Cottbus, Germany; +49-355-480-1000 (e-mail: bvusal@botmail.com). shunting arteria femoralis profunda. For central ECMO, existing aortic and venous cannulas were used.

Support after VA-ECMO implantation was initiated with a flow rate of $65 \mathrm{~mL} / \mathrm{kg}$ per minute. It was then regulated to obtain $\mathrm{SvO}_{2}$ at a level of $60 \%-70 \%$, oxygen pressure in arterial blood ( $\mathrm{PO}_{2}$ ) of 150-200 $\mathrm{mm} \mathrm{Hg}$, and carbon dioxide pressure $\left(\mathrm{PCO}_{2}\right) 35-45 \mathrm{~mm} \mathrm{Hg}$. Activated coagulation time (ACT) was maintained at 160-200 seconds. Average blood pressure was maintained at $70 \mathrm{~mm} \mathrm{Hg}$ by using adequate volume therapy and noradrenalin.

Patients were divided into 2 groups according to survival. Statistical analysis was performed by using the IBM SPSS Statistics for Macintosh, Version 25.0 (released 2017; IBM Corp., Armonk, NY, USA). We analyzed continuous variables for normally distributed samples by using the $t$ test. The chi-square test and Fisher exact test were used for categorical data. The mean values of parameters, which were analyzed at the time of follow-up, were compared.

\section{RESULTS}

Data were extracted for all patients with VA-ECMO after cardiac surgery that occurred between January 2017 and October 2017.There were 23 patients who were included in our study. Four patients were transported to another clinic where further therapy, such as LVAD or transplantation, was possible. Among the remaining 19 patients, 18 had central ECMO, and 1 patient, peripheral ECMO. Eight (42\%) survived at the end of follow-up.

The mean time on ECMO was 3 days, with a maximum of 10 and minimum of 0 . There was no remarkable difference in the 2 groups concerning mean time on ECMO (3.4 days, survivor; 3.3 days, nonsurvivor), and there was no statistical significance $(P=.8)$.

\section{Preoperative Factors}

Seven patients were admitted as emergency cases, 3 with STEMI, 6 with NSTEMI, and 2 with endocarditis. All patients with STEMI and endocarditis were nonsurvivors. Three patients were reanimated prior to operation; none of them could survive ECMO therapy.

Four $(21 \%)$ cases had peripheral arterial occlusive disease (PAOD); 2 (11\%), chronic obstructive pulmonary disease (COPD); and 2 (11\%), diabetes mellitus (DM). None of the preoperative conditions showed statistical significance for mortality.

The mean BMI and BSA, respectively, for the 2 groups were $27(\mathrm{SD} \pm 3.7), 1.88(\mathrm{SD} \pm 0.24)$ for survivors and 28 (SD 
Table 1. Follow-up of Noradrenalin Doses in Survivor and Nonsurvivor Groups

\begin{tabular}{|c|c|c|c|c|c|}
\hline & & $\mathrm{n}$ & Mean & $\pm \mathrm{SD}$ & $P$ \\
\hline \multirow{2}{*}{ Noradrenalin, preoperative } & Survivor & 0 & - & - & \multirow{4}{*}{.183} \\
\hline & Nonsurvivor & 6 & 0.50 & 0.17 & \\
\hline \multirow{2}{*}{ Noradrenalin, pre-ECMO } & Survivor & 5 & 0.36 & 0.29 & \\
\hline & Nonsurvivor & 10 & 0.61 & 0.33 & \\
\hline Noradrenalin $2 \mathrm{~h}$ after ECMO & Survivor & 5 & 0.23 & 0.14 & \multirow{2}{*}{.023} \\
\hline implantation & Nonsurvivor & 10 & 0.57 & 0.27 & \\
\hline \multirow{2}{*}{$\begin{array}{l}\text { Noradrenalin after } 24 \mathrm{~h} \text { on } \\
\text { ECMO }\end{array}$} & Survivor & 5 & 0.20 & 0.14 & \multirow{2}{*}{.851} \\
\hline & Nonsurvivor & 10 & 0.23 & 0.29 & \\
\hline \multirow{2}{*}{$\begin{array}{l}\text { Noradrenalin after } 48 \mathrm{~h} \text { on } \\
\text { ECMO }\end{array}$} & Survivor & 5 & 0.09 & 0.09 & \multirow{2}{*}{.094} \\
\hline & Nonsurvivor & 6 & 0.23 & 0.13 & \\
\hline \multirow{2}{*}{$\begin{array}{l}\text { Noradrenalin during } \\
\text { explantation }\end{array}$} & Survivor & 5 & 0.07 & 0.07 & \multirow{2}{*}{.492} \\
\hline & Nonsurvivor & 2 & 0.13 & 0.10 & \\
\hline \multirow{2}{*}{$\begin{array}{l}\text { Noradrenalin } 24 \mathrm{~h} \text { after } \\
\text { explantation }\end{array}$} & Survivor & 5 & 0.09 & 0.09 & \multirow{2}{*}{.004} \\
\hline & Nonsurvivor & 1 & 0.70 & - & \\
\hline
\end{tabular}

$\pm 3.0)$, $1.71(\mathrm{SD} \pm 0.59)$ for nonsurvivors. $\mathrm{BMI}>30$ was insignificant for mortality $(P=1.0)$.

The mean age was similar: $69(\mathrm{SD}= \pm 10)$ versus $67(\mathrm{SD}$ $= \pm 6)$; and age $>70$ years showed no significance $(P=0.181)$.

Preoperative EF $<30 \%$ was observed in 2 patients, and both were nonsurvivors. Right ventricular insufficiency was also insignificant for mortality.

Ten $(52.6 \%)$ patients had antiaggregant medication preoperatively, and it showed no statistical significance, whether for postoperative bleeding $(P=1)$ or for rethoracotomy $(P=.1)$. Rethoracotomy was performed on $6(31.6 \%)$ patients, 2 of whom survived. Postoperative bleeding within 24 hours more than 2000 $\mathrm{mL}$ was seen in $5(26.23 \%)$ patients; it showed a trend toward significance $(P=.081)$, and none of those patients survived.

\section{Factors at the Time of Operation}

The analysis of operation type showed no significance. Nine $(47 \%)$ patients received CABG; 5 (26\%), aortic valve surgery; 4 (21\%), mitral valve surgery; 4 (21\%), tricuspid valve; and $2(11 \%)$ patients were operated on for some other cause. Five (26\%) patients were operated on with more than 1 procedure, which also showed no significance $(P=.6)$. There was not a great difference among the mean values of cardiopulmonary bypass time, aorta clamping time, and reperfusion time in the 2 groups (131 minutes versus 135 minutes, 53 minutes versus 61 minutes, 64 minutes versus 51 minutes).

The dose of noradrenalin given after ECMO implantation and 24 hours after explantation showed statistical significance. The mean value was higher in the nonsurvivor group for all time intervals (Table 1).

\section{Follow-up}

At follow-up, the lactate value was significant preoperatively and 24 hours after explantation. It showed a trend
Table 2. Follow-up of Lactate Values in Survivor and Nonsurvivor Groups

\begin{tabular}{|c|c|c|c|c|c|}
\hline & & $\mathrm{n}$ & Mean & SD & $P$ \\
\hline \multirow{2}{*}{ Lactate, preoperative } & Survivor & 5 & 1.32 & 0.57 & \multirow{2}{*}{.22} \\
\hline & Nonsurvivor & 10 & 4.85 & 4.02 & \\
\hline \multirow{2}{*}{ Lactate, pre-ECMO } & Survivor & 5 & 4.15 & 1.87 & \multirow{2}{*}{.076} \\
\hline & Nonsurvivor & 10 & 7.67 & 5.11 & \\
\hline \multirow{2}{*}{$\begin{array}{l}\text { Lactate } 2 \mathrm{~h} \text { after ECMO } \\
\text { implantation }\end{array}$} & Survivor & 5 & 5.06 & 1.99 & \multirow{2}{*}{.08} \\
\hline & Nonsurvivor & 10 & 8.83 & 5.56 & \\
\hline \multirow{2}{*}{$\begin{array}{l}\text { Lactate after } 24 \mathrm{~h} \text { on } \\
\text { ECMO }\end{array}$} & Survivor & 5 & 1.76 & 0.63 & \multirow{2}{*}{.14} \\
\hline & Nonsurvivor & 7 & 6.59 & 7.47 & \\
\hline \multirow{2}{*}{$\begin{array}{l}\text { Lactate after } 48 \mathrm{~h} \text { on } \\
\text { ECMO }\end{array}$} & Survivor & 5 & 1.26 & 0.40 & \multirow{2}{*}{.19} \\
\hline & Nonsurvivor & 6 & 1.52 & 0.36 & \\
\hline \multirow{2}{*}{ Lactate during explantation } & Survivor & 5 & .75 & 0.34 & \multirow{2}{*}{.307} \\
\hline & Nonsurvivor & 1 & 1.20 & - & \\
\hline \multirow{2}{*}{$\begin{array}{l}\text { Lactate } 24 \mathrm{~h} \text { after } \\
\text { explantation }\end{array}$} & Survivor & 5 & 1.16 & 0.38 & \multirow{2}{*}{.00} \\
\hline & Nonsurvivor & 1 & 7.20 & - & \\
\hline
\end{tabular}

toward significance before $(P=.076)$ and 24 hours $(P=.08)$ after implantation (Table 2).

The value of CK during explantation showed statistical significance $(P=.006)$, with a mean value of 1.7 for survivors and 6.8 for the nonsurvivor group. The $\mathrm{CK}$ value after 48 hours on ECMO and 24 hours after explantation showed a trend toward significance, with $P=.055$ and $P=.053$, respectively (Table 3 ).

We observed no significant differences between the 2 groups concerning the pre- and post-ECMO creatinine value. Five $(26 \%)$ patients were dialyzed; 2 of them were survivors; and 3 , nonsurvivors.

CRP after 48 hours on ECMO was significant $(P=.007)$ with a mean value of 48 for survivors versus 145 for the nonsurvivor group.

There was no significant difference between the groups concerning $\mathrm{SvO}_{2}$ and $\mathrm{pH}$ at the time of follow-up.

\section{DISCUSSION}

Cardiogenic shock after cardiac surgery is still a clinical challenge, with an incidence of $2 \%$ to $6 \%$ [Biancari 2018]. VA-ECMO offers the possibility of a bridge to maintain organ perfusion and oxygenation, allowing time for the heart and lung function to recover or for transfer to more advanced therapies, such as VAD or cardiac transplantation [Nwozuzu 2016; Pappalardo 2016]. The mortality rate of patients on VA-ECMO after cardiac surgery remains high, and perioperative variables that may predict outcomes remain poorly defined [Elsharkawy 2010].

A metaanalysis that included 2986 patients (31 studies) with postcardiotomy syndrome on VA-ECMO reported a hospital survival rate of $36.1 \%$ (95\% CI, 31.5-40.8). In our 
Table 3. Follow-up of CK Values in Survivor and Nonsurvivor Groups

\begin{tabular}{lccccc}
\hline & & $\mathrm{n}$ & Mean & SD & $P$ \\
\hline \multirow{2}{*}{ CK, preoperative } & Survivor & 2 & 10.57 & 11.1 & \\
& Nonsurvivor & 9 & 16.39 & 25.2 & .76 \\
CK after 48 h on ECMO & Survivor & 5 & 6.36 & 5.8 & \\
& Nonsurvivor & 6 & 43.12 & 36.1 & .055 \\
CK during explantation & Survivor & 3 & 1.71 & 0.3 & \\
& Nonsurvivor & 1 & 6.88 & - & .006 \\
& Survivor & 3 & 1.72 & 0.7 & \\
CK 24 h after explantation & Nonsurvivor & 1 & 5.51 & - & .053
\end{tabular}

study we had a survival rate of $42 \%$. Most of the reported patients in the metaanalysis underwent peripheral cannulation [79\% of the patients (95\% CI, 73.8-84.3, 23 studies including 2652 patients)] [Biancari 2018]. In our study only one patient received peripheral VA-ECMO, and the remaining 18 were placed on central direct VA-ECMO after surgery. We did not observe any significant differences in ECMO duration (3.43 $\mathrm{SD}= \pm 1.2$ survivor; $3.27 \mathrm{SD}= \pm 2.9$ nonsurvivor).

Another metaanalysis, which was oriented to clinical outcomes of adult patients on VA-ECMO, showed that age above 65 years and pre- or post-ECMO blood lactate, renal insufficiency, longer duration of ECMO, and neurologic complications were risk factors for mortality.

In our study, lactate preoperatively and 24 hours after explantation showed statistical significance, and at other time intervals it showed a trend toward significance. In all patients who survived, lactate was lower than in nonsurvivors. At the time of follow-up, we saw decline of the lactate value for a time during VA-ECMO therapy, and we saw normalization after 48 hours in both groups (Figure 1).

Similar results at the time of follow-up were observed for the dose of noradrenalin, with significant differences in both groups during measurements at different time intervals. It also showed a decline after 48 hours and rise after explantation (Figure 2).

We did not observe any significant differences in creatinine clearance in the 2 groups, and the highest preoperative creatinine value was $185 \mu \mathrm{mol} / \mathrm{L}$. In our cohort there was no patient with high-grade renal insufficiency preoperatively. We needed to dialyze 5 patients with renal failure after postcardiotomy shock, 2 of whom survived.

The limitations of the study include the small cohort size and the study design as a retrospective study. Therefore, statistical significance when comparing mean values should be taken with caution. However, it is still possible to draw some conclusions by analyzing the differences between mean values.

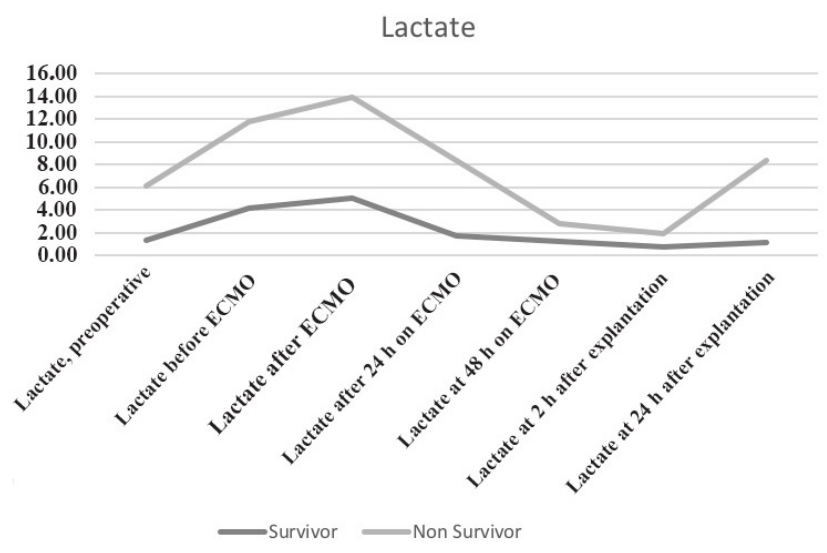

Figure 1. Lactate-value follow-up in survivor and nonsurvivor groups.

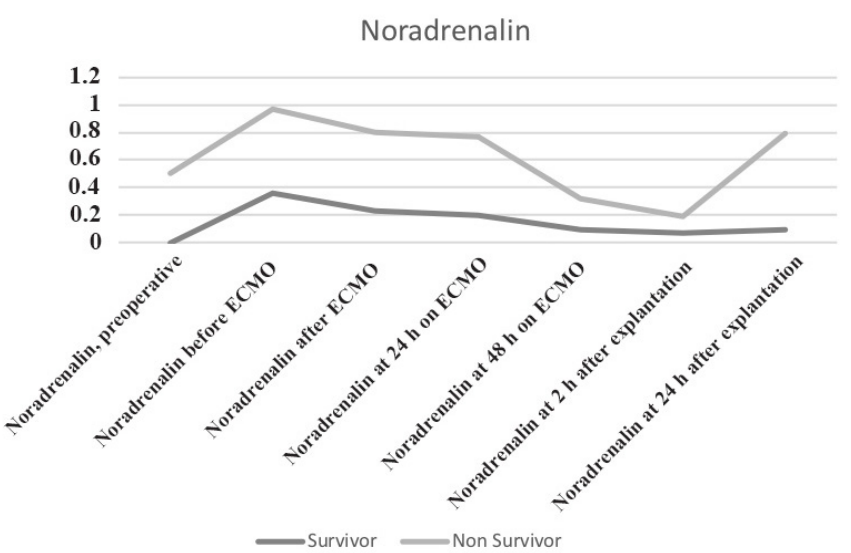

Figure 2. Noradrenalin-doses follow-up in survivor and nonsurvivor groups.

[Nwozuzu 2016; Guihaire 2017]. There are still no concrete guidelines for implantation time and VA-ECMO management [Charlesworth 2017]. Many studies were designed to identify risk factors for mortality [Rastan 2010; Biancari 2018; Wang 2018]. From those studies it is possible to identify that morbidity of the patient and age can be taken as preoperative determinants for mortality [Biancari 2018]. Lactate, which is another indicator of shock magnitude, is also a significant parameter [Rastan 2017].

It is well-known that age and preoperative morbidity are risk factors for mortality in any kind of cardiac surgery. Our study showed that patients with deep shock and massive myocardial infarction had poor prognosis. Parameters such as lactate and noradrenalin dose were significant for mortality. It can be concluded that the preoperative value of lactate and noradrenalin dose together with patient status can be used at different time intervals after ECMO implantation to evaluate further therapy.
The mortality for postcardiotomy shock remains high. It is possible to reduce it up to $40 \%$ with VA-ECMO implantation
Biancari F, Perrotti A, Dalen M, et al. 2018. Meta-analysis of the outcome after postcardiotomy venoarterial extracorporeal membrane oxygenation 
in adult patients. J Cardiothorac Vasc Anesth 32:1175-82.

Charlesworth M, Venkateswaran R, Barker JM, Feddy L. 2017. Postcardiotomy VA-ECMO for refractory cardiogenic shock. J Cardiothorac Surg 12:116.

Elsharkawy HA, Li L, Esa WA, Sessler DI, Bashour CA. 2010. Outcome in patients who require venoarterial extracorporeal membrane oxygenation support after cardiac surgery. J Cardiothorac Vasc Anesth 24:946-51.

Guihaire J, Dang Van S, Rouze S, et al. 2017. Clinical outcomes in patients after extracorporeal membrane oxygenation support for postcardiotomy cardiogenic shock: a single-centre experience of 92 cases. Interact Cardiovasc Thorac Surg 25:363-9.

Hernandez AF, Grab JD, Gammie JS, et al. 2007. A decade of short-term outcomes in post cardiac surgery ventricular assist device implantation: data from the Society of Thoracic Surgeons' National Cardiac Database. Circulation 116:606-12.

Khorsandi M, Dougherty S, Bouamra O, et al. 2017. Extra-corporeal membrane oxygenation for refractory cardiogenic shock after adult cardiac surgery: a systematic review and meta-analysis. J Cardiothorac Surg 12:55.
Muehrcke DD, McCarthy PM, Stewart RW, et al. 1996. Extracorporeal membrane oxygenation for postcardiotomy cardiogenic shock. Ann Thorac Surg 61:684-91.

Nwozuzu A, Fontes ML, Schonberger RB. 2016. Mobile extracorporeal membrane oxygenation teams: the North American versus the European experience. J Cardiothorac Vasc Anesth 30:1441-8.

Pappalardo F, Montisci A. 2016. Veno-arterial extracorporeal membrane oxygenation (VA ECMO) in postcardiotomy cardiogenic shock: how much pump flow is enough? J Thorac Dis 8:E1444-8.

Rastan AJ, Dege A, Mohr M, et al. 2010. Early and late outcomes of 517 consecutive adult patients treated with extracorporeal membrane oxygenation for refractory postcardiotomy cardiogenic shock. J Thorac Cardiovasc Surg 139:302-11, 311.e1.

Smedira NG, Blackstone EH. 2001. Postcardiotomy mechanical support: risk factors and outcomes. Ann Thorac Surg. 71(3 suppl):S60-6; discussion S82-5.

Wang L, Wang H, Hou X. 2018. Clinical outcomes of adult patients who receive extracorporeal membrane oxygenation for postcardiotomy cardiogenic shock: a systematic review and meta-analysis. J Cardiothorac Vasc Anesth 32:2087-93. 